\title{
A Comparison of the Effectiveness of Cognitive - Behavioral Couple Therapy and Acceptance and Commitment Couple Therapy in the Couple's Conflict in the City of Isfahan
}

\author{
Sahar Khanjani Veshki, ${ }^{1}$ Abdollah Shafiabady, ${ }^{2,}$ Valiyolah Farzad, ${ }^{3}$ and Maryam Fatehizade ${ }^{4}$ \\ ${ }^{1}$ Department of Counseling, Science and Research Branch, Islamic Azad University, Tehran, IR Iran \\ ${ }^{2}$ Department of Counseling, School of Psychology and Education Sceince, Allame Tabataba'i University, Tehran, IR Iran \\ ${ }^{3}$ Department of Psychology \& Counseling, Central Tehran Branch, Islamic Azad University, Tehran,IR Iran \\ ${ }^{4}$ Department of Counseling, Faculty of Psychology and Education Science, University of Isfahan, Isfahan, IR Iran \\ "Corresponding author: Abdollah Shafiabady, Department of Counseling, School of Psychology and Education Sceince, Allame Tabataba'i University, Tehran, IR Iran. E-mail: \\ ashafiabady@yahoo.com
}

Received 2016 October 16; Revised 2016 October 31; Accepted 2016 November 01.

\begin{abstract}
Background: Marriage is a social process that forms the basis and principle of human communication. In many couples, primary positive feelings decrease in time and are replaced by severe conflicts. What is of high importance is the couples' reaction to these problems. Their ability to apply problem- solving skills can be a factor in the improvement of the couples' relationship.

Methods: A quasi-experimental study with pretest, posttest design and control group was applied. The statistical population included all conflicted couples referring to consultation centers in the city of Isfahan in 2016. The subjects were recruited in voluntary form. The experimental groups included a group of cognitive-behavioral couple therapy (CBCT) (15 couples) and another group of acceptance and commitment couple therapy (ACT) (15 couples). Both groups received 12 ninety-minute sessions of therapy once a week. 15 couples were put into the control group. The study instruments were a questionnaire on demographic features and Barati and Sana'ie's questionnaire of marital conflicts. In order to analyze the data, besides descriptive statistical methods, COVARIANCE analysis was used in SPSS.

Results: The results revealed that cognitive-behavioral couple therapy and acceptance and commitment couple therapy made significant changes in conflict decrease at the posttest stage $(\mathrm{P}<0.0001)$. Also, comparing therapeutic groups implied that there is a significant difference between cognitive-behavioral couple therapy and the control group $(\mathrm{P}<0.0001)$. Furthermore, comparison of acceptance and commitment couple therapy group with the control group showed significant differences $(\mathrm{P}<0.0001)$. Comparing cognitive-behavioral couple therapy and acceptance and commitment couple therapy implied that there is no significant difference between the effects of these two therapeutic methods at the posttest stage $(\mathrm{P}>0.05)$.

Conclusions: According to the results, cognitive-behavioral couple therapy and acceptance and commitment couple therapy made significant changes in conflict decrease at the posttest stage and there was no significant difference between the effects of these two therapeutic methods at the posttest stage. Therefore, the present study provides experimental support for both therapies in order to decrease the marital conflicts.
\end{abstract}

Keywords: Conflict, Cognitive-Behavioral Couple Therapy, Acceptance and Commitment Couple Therapy

\section{Background}

Marital life is a critical part of every human's life. No one gets married with a predetermined aim to get divorced and almost all couples getting married hope to have a longlasting as well as peaceful and prosperous life. However, in the present time because of the changes in life flow, couples experience severe and vast problems in starting a communication and maintaining marital relationships. Couples' conflicts result from differences and cannot be avoided (1).

Derangement and marital conflict cause decreases in happiness, life satisfaction, and self-esteem, and problemmaking attachments among couples can increase psycho- logical derangement signs (2). An intimate marital communication includes a challenge that the couples should learn how to start communication. Since the disability in solving the conflicts leads to losing intimacy, better understanding of the conflict and helping the couples learn its constructive management is of high importance (3). Considering the effect of conflicts on the couples' communications, various methods of therapy have been presented such as cognitive-behavioral therapy, systematic therapy, emotion-based therapy, solution-oriented therapy, etc.

One of the effective therapies in the field of couples' problem solving is cognitive-behavioral couple therapy, which combines behavioral change strategies such as the skills of starting communication with cognitive restruc- 
turing (1). Cognitive-behavioral couple therapy has been formed in the past decade as an effective approach in the field of communicational problems. Like individual therapy, in order to strengthen the couples' capacity in evaluating and changing problem-making cognition, cognitivebehavioral interventions related to couples were designed to create and improve problem-solving and communicational skills (4). The most important communication skill is listening, which can cause intimate feelings to create and sustain. When you listen, you understand your spouse better; you simply empathize with him/her, and without mindreading you are able to understand the reason of your spouse's behavior. Beck (1988) states that the couples' problems come from cognitive distractions and errors, and cognitive distractions lead to the couples' severe anger and conflict (5).

One of the other recent consulting methods is acceptance and commitment-based counseling, which is due to creating a rich and meaningful life for the clients, it has caused therapists working with the families to use ACT in their therapeutic sessions as intervention. Therefore, the second therapeutic intervention in the present study is acceptance and commitment-based couple therapy. In this therapy, rather than changing the cognitions, it is attempted to increase the individual's psychological relationship with his/her thoughts and feelings and accept them instead of avoidance. In ACT, the main aim is to create psychological flexibility. The psychological flexibility in the viewpoint of ACT means the ability to have a full relationship with the present time and change or maintain the behavior for valuable and important life purposes (6). Scientific studies have reported increasing positive effect of high psychological flexibility on life quality improvement since acceptance and commitment basically have been developed for the problems such as depression and anxiety. Its major rules (acceptance here and now, defusion, self as a context and values committed action) have dramatically affected communicational issues (7).

Recent studies applying cognitive-behavioral therapy and acceptance and commitment-based couple therapy provide satisfactory results regarding the use of these approaches in treating the couples. The conducted studies have suggested cognitive-behavioral couple therapy as a suitable treatment for marital intimacy (8), marital conflicts (9) and satisfaction with a relationship (10). Furthermore, acceptance and commitment couple therapy has been discussed as an effective method in couples' marital attribution (11), marital conflicts (12), and couples' adjustment and satisfaction increase and mental and interpersonal derangement decrease (13). However, despite the promising results, experimental evidence for applying the cognitive-behavioral couple therapy and acceptance and commitment-based couple therapy as treatment methods for conflicts is limited. Cognitive-behavioral couple therapy and acceptance and commitment therapy have some differences. For instance, in the Cognitive-behavioral couple therapy, the problem stems from irrational beliefs (14) while in the acceptance and commitment therapy, the problem-making area roots in thoughts, feelings, memories, etc., which are attempted to be controlled rather than experienced (15). Therefore, in the present study, the effectiveness of cognitive-behavioral couple therapy was compared with that of acceptance and commitment couple therapy in the couples' conflicts in the city of Isfahan.

\section{Objectives}

Maintaining and promoting the couples' suitable relationships depend on their interaction manner. Since the couples have high interaction, it is possible for conflicts to be created among them in their marital life. Conflict is considered a kind of stress-making and threatening condition for the couples. Conflict in every intimate relationship is unavoidable; by decreasing conflicts, the couples' relationships will improve and the life quality promotes. Considering the importance of conflicts in marital relationships, in the present study the effectiveness of cognitive-behavioral couple therapy and acceptance and commitment couple therapy in the couples' conflicts was investigated and compared in the city of Isfahan.

\section{Methods}

The present research was a quasi-experimental study designed as pretest, posttest, with a control group. The independent variables were cognitive-behavioral couple therapy and acceptance and commitment couple therapy and the dependent variable was marital conflict.

The statistical population of the study included all conflicted couples referring to consulting centers in Isfahan in 2016. The subjects were recruited in the current study in voluntary form. In order to making the sample, a notice was announced about holding couple therapy sessions in a number of Isfahan consultation centers (under the supervision of the organization of wellbeing). At the first stage, the referred people were registered, and then interviewed by the researcher. The test was administered on them and the study samples were selected regarding the inclusion and exclusion criteria among the qualified couples. Hence, 45 couples were selected and randomly put into three groups including CBCT (15 couples), ACT (15 couples), and a control group (15 couples). The inclusion criterion included the couples who: did not refer to family court aiming at getting divorced, did not suffer from 
chronic mental-personality disorders, did not simultaneously participate in psychological and psychiatric interventions, had at least a year of shared life record, had at least high school diploma degree, both could participate in twelve successive sessions. Exclusion criteria included: absence in more than three sessions, not doing the homework during the couple therapy, occurring unpredicted events (such as sickness, death, etc.) and lack of tendency to cooperate.

In order to carry out the present study, the scientific texts and references were studied at first to develop consultation sessions according to CBCT and ACT theories. Afterwards, the techniques and patterns of consultation sessions were provided and compiled, then confirmed by specialists. The CBCT framework was designed by the researcher according to Mckay, Fanning and Paleg (5), Dattilio (16), and Azimi Far (7). Twelve ninety-minute group sessions were held on CBCT once a week. The ACT framework was designed by the researcher according to the works of Russ Harris (17), Russ Harris, translated by Fatehi Zade and Azimi Far (18), and the workshop of valuable relationships by Izadi and Abedi, faculty of psychology and educational sciences, Isfahan university (2014). Twelve ninety-minute group sessions were administered on ACT once a week. Following the treatment, the subjects responded again to the study instruments at the end of the sessions. In order to analyze the data, besides descriptive statistical methods, COVARIANCE analysis was used in SPSS software.

In order to observe the moral considerations, the subjects were assured that the collected data will be used merely consistent with the present study and in order to be certain about the information privacy in the questionnaires, they could avoid writing down their full name and use the code instead. Moreover, the control group subjects were agreed to be put under the effect of independent variable after finishing educational sessions of the experimental group and the data analysis.

\subsection{Assessment Instrument}

\subsubsection{Questionnaire of Demographic Features}

In order to collect the subjects' personal information, the questionnaire of demographic features was designed. In this questionnaire, information such as age, education level, occupation, marriage duration, number of children, etc. were examined.

\subsubsection{Questionnaire of Marital Conflict by Barati and Sana'ie}

In the present study, conflict was measured based on the scores the subjects got in Barati and Sana'ie's marital conflict questionnaire (1996). It has 42 questions estimating the severity of marital conflict. The range of total score of the questionnaire is from 42 to 210 . High scores in this test imply conflict severity and unsuitability of condition and low scores show the goodness of condition. This test was designed by Barati and Sana'ie (1996). In order to determine the questionnaire's content and face validity, it was administered to a group of 111 individuals composing of 53 males and 58 females referring to judicial authorities and consultation centers to solve their conflict and also a group of 108 couples including 53 males and 55 females. Comparing the means of two adaptive and maladaptive groups in men and women showed a significant difference in marital conflict that implies the test differentiation power in diagnosing conflicted and non-conflicted couples. The reliability of this questionnaire was achieved as 0.53 by Barati and Sana'ie (19). In the present study, Cronbach's alpha method was used to investigate the questionnaire's reliability coefficient that was obtained as 0.58 .

\subsection{Interventions}

\subsubsection{Cognitive-Behavioral Couple Therapy (CBCT)}

A summary of CBCT sessions is as follows: first session (starting communication and making subjects ready): good relationship, teaching and making the couples familiar with cognitive-behavioral model, evaluating change motivation, sessions objectives; second session (behavioral skills): role play technique, knowing spouses' reinforcement and punishment models, increasing positive behavioral exchange and reinforcement, decreasing negative behavioral exchange and punishment; third session (behavioral skills): dependence contracts, role reversal; fourth session (behavioral skills): training assertiveness, behavioral experiments, behavioral practice; fifth session (communicational skills): active listening, evaluating message sender and receiver faults, practicing message sender and receiver skills; sixth session (communicative skills): determining specific negative interactions, practicing efficient communication skills; seventh session (cognitive factors): descending arrow in evaluating cognitions, recognizing automatic thoughts and associated emotions and behaviors; eighth session (cognitive factors): recognizing schemata and effect on spouses; ninth session (cognitive factors): investigating the manner of perception and clarification of spouse's behavior, modifying cognitive errors and replacing rational beliefs; tenth session (cognitive factors): identifying couples' attribution patterns, clarifying the objectives and unrealistic expectations about the self and the spouse; eleventh session (problem-solving skills): evaluating the couples' problem-solving skills, practicing and learning problem-solving skills, programming activity, and twelfth session (conflict-solution skills): investigating the couples' conflicts and conflict-solution styles, teaching and practicing conflict-solution methods. 


\subsubsection{Acceptance and Commitment Couple Therapy (ACT)}

A summary of ACT sessions is as follows: first session (making communication and making subjects ready): introduction, specifying expectations and objectives, manner of holding sessions, primary contracts; second session (conceptualizing the problem): making a good relationship, investigating the problem and conceptualizing the problem from the viewpoint of members and consultation; third session (selecting between staying and going): selection, healthy communication levels (openness, concentration, and eagerness); fourth session (1. Couples' problem): first psychological toxin: mind engagement, first antitoxin: getting rid of mind; fifth session (2. couples' problem): second psychological toxin: highlighting the expectations, second antitoxin: weakening expectations (not removing them); sixth session (3. The couples' problem): third psychological toxin: ambiguous values, third antitoxin: clear value and dominating the skills to move along with the values (conflict-solution and effective communication); seventh session (4. Couples' problem): fourth psychological toxin: cutting communication, fourth antitoxin: uniting with the spouse (openness, acceptance, and curiosity); eighth session (5. Couples' problem): fifth psychological toxin: attempting to avoid, fifth antitoxin: tending to suffer, introducing control methods; ninth session (values): couple values, identifying impediments against values, choosing couple value and making it objective; tenth session (action impediments and antitoxin of internal impediments): identifying action impediments, acceptance and defusion as the antitoxin of internal impediments of change; eleventh session (antitoxin of external impediments): problem-solving as the antitoxin of external impediments of change and; twelfth session (psychological fog): introducing psychological fog (what happens when you mix with your thoughts), introducing psychological fog layers (layer of musts, there is nowhere to try, if only, just if.., painful past, scary future, etc.).

\section{Results}

The results on demographic characteristics revealed that the most frequent age range was 31 - 35 years (12.22\%) in the CBCT experimental group, 25 - 30 years (15.56\%) in the ACT experimental group, and 31 - 35 years (12.22\%) in the control group. Among the couples participating in the CBCT and ACT experimental groups, the most frequent education level belonged to BA degree $(14.44 \%$ and $10 \%$, respectively), while in the control group it was high school diploma (11.11\%).

The obtained results imply that the mean scores of marital conflicts decreased in the CBCT and ACT exper- imental groups compared to the control group at the posttest stage (Table 1$)$.

Prior to offering the results of inferential statistics, the statistical presuppositions were addressed. As the results of Shapiro Wilk and Kolmogorov Smirnov tests showed, the supposition of normality of data distribution is established $(\mathrm{P}>0.05)$ (Table 2 ). Also, as a COVARIANCE analysis presupposition, the homogeneity of regression was examined and the result proved the insignificancy of regression $(\mathrm{P}>0.05)$.

Based on the inferential analysis, independent variables (CBCT and ACT training) could lead to significant differences in the mean scores of dependent variable (marital conflict) at the posttest stage at the error level of 0.05. The effect size of CBCT and ACT on the degree of marital conflict at the posttest stage was 0.48 ; that is to say that $48 \%$ of the changes in the dependent variable is explained by group membership (Table 3).

Both groups of CBCT and ACT have significant differences with the control group $(\mathrm{P}<0.0001)$, while the difference between CBCT and ACT experimental groups was not significant $(\mathrm{P}>0.05)$ (Table 4).

\section{Discussion}

There is a potential for conflicts in every human and it is natural to have some maladjustment in every relationship. Some couples experience more conflicts compared to others and some are able to treat conflicts constructively. Conflicted couples show high degree of negative affections, complaints, and isolation compared to efficient couples, which is due to their inability to solve the conflicts. Conflict can destroy a good and even loving marriage. On the other hand, conflict management can alleviate tensions and put people together more than before (20). CBCT was introduced as the first effective treatment to decrease the couples' conflicts. CBCT provides an opportunity for the couples to be able to learn necessary methods to identify and modify self-destructive thoughts and behaviors (21). Most of the experimental evidence show that couples having problem use various negative and ineffective patterns to start a communication in stating thoughts and feelings, listening, and problem solving skills (4). Therefore, basic types of cognitive-behavioral couple interventions are used to decrease negative behavior and increase positive behavior. This approach is supported in studies on the improvement of family performance (22).

Recently, ACT, has been used as an effective therapy for couple problems. Along with creating happiness, every intimate relationship faces the couples with sadness and pain while psychological flexibility in ACT can assist the 
Table 1. Mean and Standard Deviation of Marital Conflict Scores in CBCT and ACT Experimental Groups and Control Group at Pretest and Posttest Stages

\begin{tabular}{l|c|c|c|}
\hline Marital Conflict & Pretest & Posttest & P Value \\
\hline CBCT experimental group & $108.33(10.31)$ & $89.60(8.60)$ & 0.0001 \\
\hline ACT experimental group & $108.53(12.12)$ & $107.76(9.23)$ & \\
\hline Control group & $110.10(13.75)$ & & \\
\hline \multicolumn{2}{l}{} \\
\hline
\end{tabular}

Table 2. The Results of Levin Test Regarding the Presupposition of Equality of Variances in CBCT and ACT Experimental Groups and Control Group

\begin{tabular}{lcccc}
\hline Variable & F & First Degree of Freedom & Second Degree of Freedom & Significance \\
\hline Marital conflicts & 0.04 & 2 & & 87 \\
\hline
\end{tabular}

Table 3. COVARIANCE Analysis to Compare the Effect of CBCT and ACT on Marital Conflict

\begin{tabular}{|c|c|c|c|c|c|c|c|}
\hline Statistical Indexes/Variables & Square Sum & Degree of Freedom & Square Mean & $\mathbf{F}$ & Significance Level & Effect Size & Test Power \\
\hline Pretest & 249.82 & 1 & 249.82 & 2.89 & 0.09 & 0.03 & 0.39 \\
\hline Group membership & 6890.97 & 2 & 3445.48 & 39.93 & 0.0001 & 0.48 & 1 \\
\hline Error & 7419.54 & 86 & 86.27 & & & & \\
\hline Total & 835623 & 90 & & & & & \\
\hline
\end{tabular}

Table 4. A summary of Bonferroni Follow-Up Test Results in Marital Conflict Variable

\begin{tabular}{|c|c|c|}
\hline Groups & Means (SD) & Significance Amount \\
\hline \multicolumn{3}{|l|}{ CBCT experimental group } \\
\hline ACT experimental group & $0.37(2.39)$ & 0.98 \\
\hline Control group & $-18.41(2.40)$ & 0.0001 \\
\hline \multicolumn{3}{|l|}{ ACT experimental group } \\
\hline CBCT experimental group & $-0.37(2.39)$ & 0.98 \\
\hline Control group & $-18.78(2.40)$ & 0.0001 \\
\hline \multicolumn{3}{|l|}{ Control group } \\
\hline CBCT experimental group & $18.41(2.40)$ & 0.0001 \\
\hline ACT experimental group & $18.78(2.40)$ & 0.0001 \\
\hline
\end{tabular}

couples in passing through these challenges (23). The couples should reach the status of bearing resentment that includes awareness of the fact that the resentment is the natural part of human's status. Therefore, tendency to resent provides a basis to start long-term communication with people and moving along with values can create a healthy life (17). These clarifications have been supported by the studies aimed at increasing satisfaction and marital performance and decreasing obsession signs (24). In the present study, this approach was compared to the former approach, i.e. cognitive-behavioral couple therapy, in order to decrease the marital conflicts. The results implied the effectiveness of CBCT and ACT in marital conflicts $(\mathrm{P}<$
0.0001). These results were consistent with those of former studies on the application of CBCT in the field of marital conflicts conducted by Hediati Azar (25) and Vakili et al. (9). Also, they are in agreement with the findings of previous studies investigating the effect of ACT on the marital conflicts carried out by Yousefi (26), Kashefi and Honar Parvaran (12), and Arab Nejad, Birashk, and Abol Ma'ali (27). Moreover, both CBCT and ACT methods did not show any significant difference at the posttest stage $(\mathrm{P}>0.05)$. Hence, it can be concluded that there is no significant difference between the effects of these two therapeutic methods on couples' conflicts.

One of the explanations for the study results is that 
CBCT and ACT have similarities; however, these similarities are clarified through different alternatives in each treatment. CBCT and ACT both emphasize good therapeutic relationship and the role of cognition through different routes. Cognitive-behavioral couple therapists emphasize cognition change (15), while acceptance and commitment therapists, through emphasizing the role of cognition, intend to change the context wherein the thoughts occur (28). In other words, CBCT and ACT are distinguished where they emphasize the role of cognition so that in CBCT the questions are related to the thought correctness, but in ACT the questions are more related to the manner of the individual's communication to specific thoughts and cognitive mixing (23). The other similarity in CBCT and ACT is that both emphasize behavior change, and in order to change the behavior, they apply problem solving skills, conflict solution skills, and communicational skills in couple therapy sessions. In ACT sessions, the couples are encouraged to move along with values and commitment to behavioral change through above-mentioned skills.

Studies on the effect of ACT on marital life-related variables are still at initial stages and more evidence is required regarding the action mechanism of this therapy and its outcomes compared to СВCT. The results of this study imply that taking into account the similarity of both therapies in applying problem-solving, conflict solution, and communicational skills and their concentration on the couples' cognition and behavior, although through different strategies, CBCT and ACT can be suitable therapy options to decrease the couples' conflicts in Iran.

The voluntary participation in this study might affect the results acquired from statistical analysis and consequently adversely affected the internal validity of the study. Therefore, in generalizing and emphasizing the study results, this limitation must be taken into account. It is clear that through conducting similar studies and confirming the findings, this limitation will be eliminated practically. Among the other limitations is that the statistical population of the study included the couples in the city of Isfahan and therefore generalizing the results of this study to the other societies should be conducted cautiously. It is also suggested to compare the effectiveness of CBCT and ACT in different cities of Iran and investigate the effect of these two approaches on other variables, as well. The findings of this study can be effective in couples' conflicts reduction, marital life enrichment, problems acceptance instead of avoidance, and also skills inventory increase in couples' life. The results of the present study can also be used at family consultation centers, mental hygiene services center, centers of crisis intervention, and family courts.

\section{Acknowledgments}

This study was extracted from a Ph.D. thesis by Ms. Sahar Khanjani Veshki. Parse consultation center principal is sincerely acknowledged because of providing the condition of administering and attracting clients; also, we are grateful to all the couples who helped us with the present study.

\section{Footnotes}

Authors' Contribution: Ph.D. student, paper extraction from the thesis: Sahar Khanjani Veshki; professor and corresponding author: Abdollah Shafiabadi; assistant professor of the thesis regarding thesis data analysis and paper: Valiyolah Farzad and thesis assistant professor regarding necessary modifications to improve the thesis and paper: Maryam Fatehizade.

Conflict of Interest: There was no conflict of interest among the authors and the budget of thesis administration and paper preparation and other related charges were paid by Sahar Khanjani Veshki (Ph.D. student).

\section{References}

1. Halford WK. Brief therapy for couples: Helping partners help themselves. New York: Guilford press; 2001.

2. Hawkins DN, Booth A. Unhappily Ever After: Effects of long-term, lowquality marriages on well-being. Social Forces. 2005;84(1):451-71. doi: 10.1353/sof.2005.0103.

3. Kaslow FW. Divorce: An evolutionary process of change in family system.J Divorce. 1994;7(3):21-39. doi:10.1300/J279v07n03_02.

4. Dattilio F, Birashk B. Couples' cognitive behavioral therapy- first part. J Cognitive Sci. 2006;8(2):72-81.

5. McKay M, Fanning P, Paleg K. Couple Skills: Making Your Relationship Work. Oakland: New Harbinger Publications; 2006.

6. Gregg JA, Callaghan GM, Hayes SC, Glenn-Lawson JL. Improving diabetes self-management through acceptance, mindfulness, and values: a randomized controlled trial. J Consult Clin Psychol. 2007;75(2):336-43. doi: 10.1037/0022-006X.75.2.336. [PubMed: 17469891].

7. Azimifar S. A comparison of the effect of cognitive-behavioral couple therapy and ACT based approach on happiness and marital satisfaction, a study on a single case. Iran, Isfahan: Faculty of psychology and educational sciences: Isfahan University; 2014.

8. Ghiasizade M, Karimiyan M. effectiveness of Cognitive-behavioral group couple therapy on the couples' intimacy in the city of Ahvaz. J Periodical Informing. 2014;9(29):27-31.

9. Vakili M, Kimiaee A, Fathizade M, Mashhadi A. Comparing the Effectiveness of Emotion-Oriented Couple Therapy and CognitiveBehavioral Couple Therapy on Marital Conflict among Couples. Int Review in Life Sci. 2015;5(11):155-63.

10. Monson CM, Fredman SJ, Macdonald A, Pukay-Martin ND, Resick PA, Schnurr PP. Effect of cognitive-behavioral couple therapy for PTSD: a randomized controlled trial. JAMA. 2012;308(7):700-9. doi: 10.1001/jama.2012.9307. [PubMed: 22893167]. 
11. Soboohi R. codifying couple consultation package based on ACT and its effect on the improvement of marital attribution in women referring to community centers in the city of Isfahan. Iran, Isfahan: Faculty of educational sciences and psychology: Isfahan university; 2014.

12. Kashefi Z, Honarparvaran N. Evaluate The Effectiveness Of Couples Therapy Based On Commitment And Acceptance (ACT) On Reducing Marital Conflict Working Couples In Isfahan Education.J Biol Alied Sci. 2015;4(10):213-20.

13. Peterson B, Eifert G, Feingold T, Davidson S. Using Acceptance and Commitment Therapy to Treat Distressed Couples: A Case Study With Two Couples. J Cognitive and Behav Practice. 2009;16:430-42. doi: 10.1016/j.cbpra.2008.12.009.

14. Mohammadi A, Zargar F, Omidi A, Mehrabi A, Akbari M, Begholi H An introduction to the third generation (cognitive-behavioral therapies). Tehran: Arjmand; 2015.

15. Hofmann SG, Asmundson GJ. Acceptance and mindfulness-based therapy: new wave or old hat? Clin Psychol Rev. 2008;28(1):1-16. doi 10.1016/j.cpr.2007.09.003. [PubMed:17904260].

16. Dattilio F. Cognitive-Behavioral Therapy with Couples and Families: A Comprehensive Guide for Clinicians. New York: Guilford Publications; 2010.

17. Harris R. ACT with Love: Stop Struggling, Reconcile Differences, and Strengthen Your Relationship with Acceptance and Commitment Therapy. Oakland: New Harbinger Publications; 2009.

18. Harris R. in seeking for happiness. Tehran, Iran: Avije pub; 2014.

19. Sana'ie B. The scale of family assessment and marriage. Tehran, Iran: Be'sat pub; 2000.

20. Fincham FD, Beach SR, Davila J. Forgiveness and conflict resolution in marriage. J Fam Psychol. 2004;18(1):72-81. doi: 10.1037/0893-
3200.18.1.72. [PubMed: 14992611].

21. Hawton K, Salkovskis PM, Kirk J, Clark D. Cognitive Behaviour Therapy for Psychiatric Problems: A Practical Guide. Tehran, Iran: Arjmand; 2003.

22. Shaker A, Narimani M, Afrooz GA, Hasani F, Baghdasarians A. Effectiveness of cognitive-behavioral couple therapy on performance improvement in the families of the couples asking for divorce. J Periodical of Nasim-E-Tandorost. 2013;2(1):56-63.

23. Dahl J SI, Martell C, Kaplan JS, Walser RD. ACT and RFT in Relationships: Helping Clients Deepen Intimacy and Maintain Healthy Commitments Using Acceptance and Commitment Therapy and Relational Frame Theory. Oakland: New Harbinger Publications; 2014.

24. Alireza'ie A. Investigating the effectiveness of act based couple therapy on the increase of marital satisfaction and performance and decrease of obsession signs in the couples suffering from obsessive compulsive disorder. Iran: Najaf Abad Islamic Azad University; 2015.

25. Hedaiati-Azar M. investigating the effect of cognitive-behavioral couple therapy on the decrease of women's marital conflicts in zone 5 of Tehran. Terhan, Iran: Payam-E-Nour University; 2012.

26. Yousefi $Z$. Investigating the effect of act on the decrease of marital conflicts. Iran: Isfahan University; 2015.

27. Arabnejad S, Birashk B, Abolmaali K. The effectiveness of Acceptance and Commitment Therapy (ACT) on increasing Marital Intimacy and decreasing Marital Conflicts between the Couples of Tehran. J Social Issues \& Humanities. 2014;8(2):89-93.

28. Hayes SC, Strosahl KD. A practical Guide to Acceptance and Commitment therapy. New York: Springer Science and Business Media Inc; 2010. 